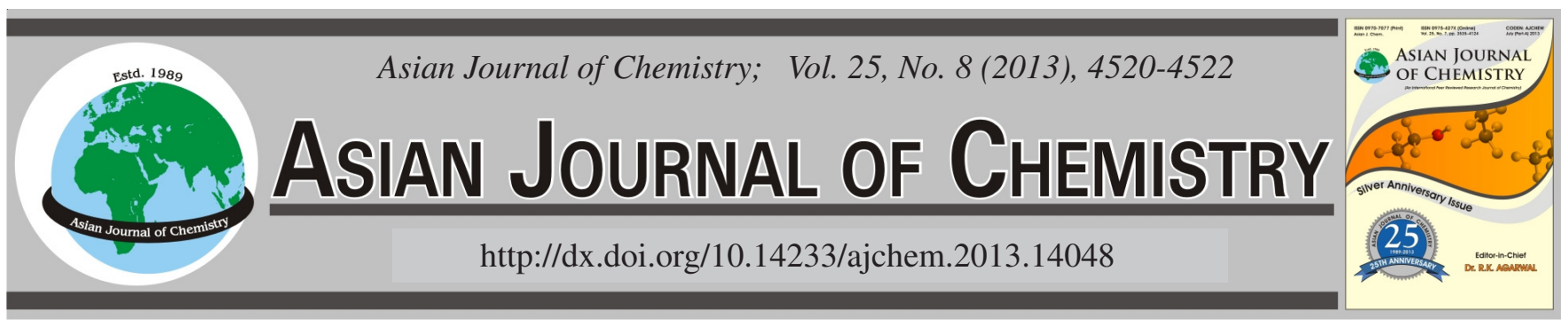

\title{
Synthesis of $\delta$-Decalactone
}

\author{
Jia Bu, Guangxue Li*, Mingzhu Zhao, Jiaming Li, Feng Jiang, Hualu Zhan and Yang Chu
}

Institute of Chemical Engineering, Anhui University of Science and Technology, Huainan 232001, P.R. China

*Corresponding author: E-mail: gxli@aust.edu.cn

\begin{abstract}
The application and shortcomings of typical synthetic method of title $\delta$-decalactone was introduced in brief. A synthesis of 2-pentylidene cyclopentanone starting from cyclopentanone and $n$-valeraldehyde through aldol condensation, followed by dehydration, was studied and the yield reached $86.3 \%$. Then 2-pentenyl cyclopentanone was prepared in a yield of $91.5 \%$ from 2-pentylidene cyclopentanone with a hydrogenation methodology under atmospheric pressure and use Pt/C as catalytic. Through Baeyer-Villiger oxidation, $\delta$-decalactone was synthesized in a yield of $61.2 \%$. Experiments by orthogonal experiment method to optimize the reaction conditions to determine the response of a reasonable process parameters and the analysis of the factors affecting the reactions. The structures and compositions of these compounds were accomplished by IR and GC-MS.
\end{abstract}

Key Words: $\delta$-Decalactone, Cyclopentanone, $n$-Valeraldehyde, Synthesis.

\section{INTRODUCTION}

$\delta$-Decalactone is a colourless or light yellow liquid with a strong aroma of sweet cream and nuts, strong fragrant flowers at the end. It is the main component of natural fragrant cream, mainly used for modulating food flavor, specifically for soft drinks, ice cream, candy, milk, dairy products, biscuits, condiments and bakery products ${ }^{1}$. The product is also an important high-grade feed additive, feed flavor can improve and improve livestock and poultry rapid growth. As a natural cream containing a large number of animal fat, too much inhalation can lead to cardiovascular disease. So $\delta$-decalactone plays an important role to protect people's health when we add cream spices to vegetable oil as margarine which used in food industry $^{2}$. Therefore, to discuss $\delta$-decalactone's chemical synthesis methods and synthesis techniques have the great meaning.

About the synthesis of $\delta$-decalactone, together in two ways: first, through all kinds of means synthetic $\delta$-hydroxy acid and then esterification resulted $\delta$-lactone $e^{3,4}$. The source of the raw materials is difficult, can't series production or some reaction route is too long, the total yield is low, it is difficult to realize the industrialization production ${ }^{5}$. Second, first synthesic 2-pentylidene cyclopentanone this intermediate and then by Baryer-Villiger oxidation get $\delta$-lactone ${ }^{6}$. The main disadvantage of this method is that 2-pentylidene cyclopentanone during the Baryer-Villiger oxidation of ring expansion reaction may take place reverse insertion reaction and the by-product is the $\delta$-decalactone isomer, it is difficult to remove and harsh reaction conditions, the slightest mistake can cause the product purity is not high ${ }^{7}$. In addition, on the Baryer-Villiger oxidation, traditional oxidants as potassium peroxydisulfate or peracetic acid, but because they are not safe, by-products are more $\delta$-hydroxy acid, the yield is not high. The use of $\mathrm{H}_{2} \mathrm{O}_{2}$ as an oxidant and its by-product is water, do not pollute the environment and safe, inexpensive, clean product, so it obtains more and more attention. But the activity of $\mathrm{H}_{2} \mathrm{O}_{2}$ relatively peracetic acid is weak, generally add catalyst to provide reaction activity when used. Therefore, to develop some appropriate and efficient catalyst is particularly important ${ }^{8}$.

\section{EXPERIMENTAL}

Germany Brook, the VECTOR33 Fourier transform infrared spectrometer, Japanese Shimadzu company QP-50SOA GC-MS, Reagents used were analytical grade.

Synthesis of 2-pentylidene cyclopentanone: Add $25 \mathrm{~mL}$ the mass fraction of $1 \% \mathrm{NaOH}$ solution and $0.7 \mathrm{~g}$ polyethylene glycol-600 to neck flask, heating up to $30^{\circ} \mathrm{C}$, dropping $19.8 \mathrm{~g}$ cyclopentanone within $0.5 \mathrm{~h}$. Colour of solution gradually from colourless into orange. And stirring at $30^{\circ} \mathrm{C}$ slowly dropping $n$-valeraldehyde $11 \mathrm{~g}, c a .1 .5 \mathrm{~h}$ dropwise, the solution colour changed from orange to brown and after dropping to maintain the temperature $30^{\circ} \mathrm{C}$, stirred $2 \mathrm{~h}$. Cooling, add $36 \%$ acetic acid adjusted $\mathrm{pH}$ for 6 to 7 . In the separatory funnel stratification, the upper for organic layer, the lower the inorganic layer. Toluene extraction of inorganic layer, layered, the upper toluene layer, the lower layer for waste water. Combined 
organic layer and toluene layer, add the flask with a water separator, add $0.2 \mathrm{~g}$ oxalic acid, heat and stir until no more moisture out, cooling, washing with saturated salt water and $5 \% \mathrm{NaHCO}_{3}$, atmospheric distillation out toluene, residues in the $98-100{ }^{\circ} \mathrm{C} / 400 \mathrm{~Pa}$ distillation a yellow solution of 2pentylidene cyclopentanone. By GC-MS analysis, the yield ca. $86.3 \%$.

Synthesis of 2-pentenyl cyclopentanone: Add $5 \mathrm{~g}$ 2pentylidene cyclopeantanone, $0.2 \mathrm{~g}$ catalyst of $\mathrm{Pt} / \mathrm{C}$ and $40 \mathrm{~mL}$ ethanol to the atmosphere of the reactor which in $\mathrm{N}_{2}$. Sealing device and using $\mathrm{N}_{2}$ to wash, ensure the device does not contain other gases. Then normal pressure ventilation with $\mathrm{H}_{2}$, control temperature $50{ }^{\circ} \mathrm{C}, c a .20 \mathrm{~h}$ the reaction is completed. A few times before hydrogenation faster, when no hydrogen, filter the catalyst in reaction, the catalyst washed with ethanol and set aside. Rotating evaporation of anhydrous ethanol, vacuum distillation, collect $82-83^{\circ} \mathrm{C} / \mathrm{Pa}$ fractions, light yellow solution of 2-pentenyl cyclopentanone. By GC-MS analysis, the yield is ca. $91.5 \%$.

Synthesis of $\boldsymbol{\delta}$-decalactone: Add $10 \mathrm{~g}$ 2-pentenyl cyclopentanone, $30 \mathrm{~mL}$ methanol, $2 \mathrm{~mL}$ concentrated sulfuric acid to the falsk which was equipped with condenser, thermometer, magnetic stirrer, stirring and heating to $50{ }^{\circ} \mathrm{C}$ or so, dropping $32 \mathrm{~g} \mathrm{H}_{2} \mathrm{O}_{2}$ (ca. $2.5 \mathrm{~h}$ ), after dropping maintain the reaction temperature $50{ }^{\circ} \mathrm{C}$ stirring $1.5 \mathrm{~h}$, the solution slowly from light yellow to colorless and appear cloudy. Layer, upper for organic layer, lower for inorganic. Inorganic layer extracted several times by adding $10 \mathrm{~mL}$ toluene, layered, the upper toluene layer, the lower for waste water the combined organic layers toluene layer with $5 \% \mathrm{NaHCO}_{3}$ solution, washed to $\mathrm{pH} 7-8$, then washed several times with brine $10 \mathrm{~mL}$, layered, the upper organic layer, the lower layer of waste brine. Organic layer vacuum distillation, collecting $118-120{ }^{\circ} \mathrm{C}$ distillate, $\delta$ decalactone. By GC-MS analysis, the yield was $61.2 \%$. The infrared spectral data of the products are given below:

\begin{tabular}{cc} 
Infrared spectral data of 2-pentylidene cyclopentanone \\
\hline Wave number $\left(\mathrm{cm}^{-1}\right)$ & Characteristic absorption \\
\hline 2869 and 2868 & $-\mathrm{CH}_{3},-\mathrm{CH}_{2}$ \\
2958 & $-\mathrm{H}$ on the double bone \\
1722 & $\mathrm{C}=\mathrm{O}$ \\
1649 & $\mathrm{C}=\mathrm{C}$ \\
\hline Infrared spectraal data of 2-pentenyl cyclopentanone \\
\hline Wave number $\left(\mathrm{cm}^{-1}\right)$ & Characteristic absorption \\
\hline 2927 and 2861 & $-\mathrm{CH}_{3},-\mathrm{CH}_{2}$ \\
1703 & $\mathrm{C}=\mathrm{O}$ \\
\hline Infrared spectral data of $\delta$-decalactone \\
\hline Wave number $\left(\mathrm{cm}^{-1}\right)$ & Characteristic absorption \\
\hline 2931 and 2868 & $-\mathrm{CH}_{3},-\mathrm{CH}_{2}$ \\
1711 & $\mathrm{C}=\mathrm{O}$ \\
1244 & $\mathrm{C}-\mathrm{O}$ \\
\hline
\end{tabular}

\section{RESULTS AND DISCUSSION}

\section{2-Pentylidene cyclopentanone synthesis condition}

Temperature on the reaction: Temperature is an important factor that influences the direction and speed of response of chemical reaction ${ }^{9}$. Fixed cyclopentanone $19.8 \mathrm{~g}, n$-valeraldehyde $11 \mathrm{~g}$ and a certain amount of phase transfer catalyst, $25 \mathrm{~mL}$ of $1 \mathrm{wt} \% \mathrm{NaOH}$ solution, changing the system temperature to study the temperature on the reaction.

Temperature on the reaction: Fig. 1 showed cyclopentanone and $n$-valeraldehyde being can react at $0{ }^{\circ} \mathrm{C}$. As the reaction temperature increases, the yield of product 2-pentylidene cyclopentanone also increased, to $30^{\circ} \mathrm{C}$ maximum. Temperature continues to rise, the yield changed little, but because of high temperature will speed up cyclopentanone and $n$ valeraldehyde are cross-condensation product of increased purity of the product will be correspondingly reduced ${ }^{10}$. Therefore, $30^{\circ} \mathrm{C}$ is reasonable parameters.

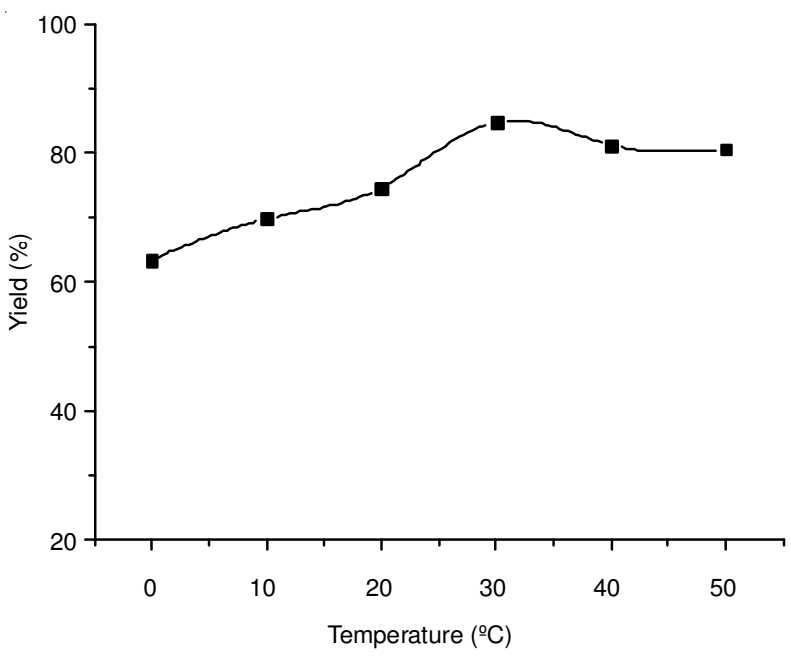

Fig. 1. Temperature on the reaction

Raw material input ratio on the reaction: At $30^{\circ} \mathrm{C}, 25$ $\mathrm{mL}$ of $1 \mathrm{wt} \% \mathrm{NaOH}$ solution, $19.8 \mathrm{~g}$ cyclopentanone, a certain amount of phase transfer catalyst, changing the $n$-valeraldehyde input, study material input ratio on the reaction. The results shown in Fig. 2.

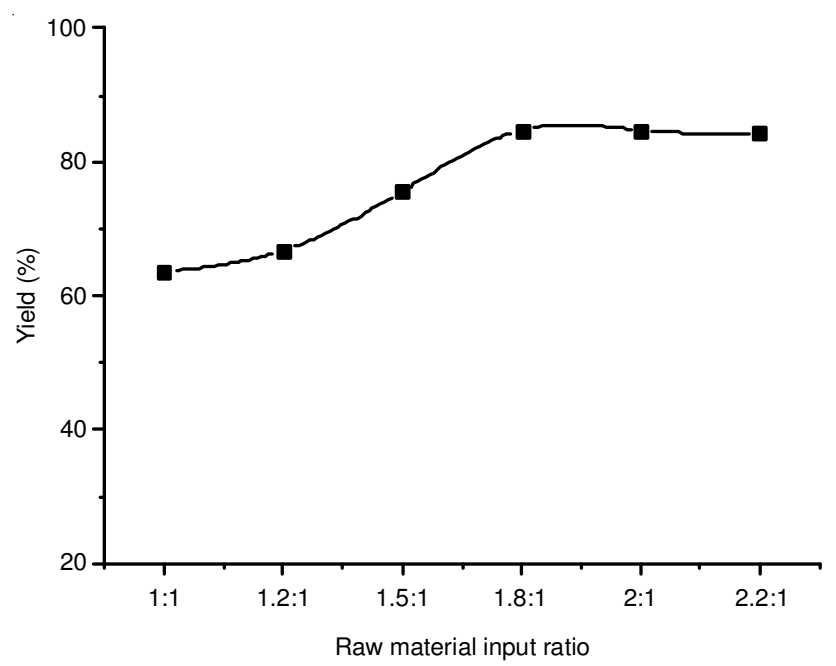

Fig. 2. Raw material input ratio on the reaction

As the aldehyde condensation reaction between aldehydes and ketones is greater than the activity of the condensation reaction between the activity in order to avoid excessive side 
effects occur, must be excessive ketones ${ }^{11}$. From the figure, $n$ (cyclopentanone) $: n(n$-valeraldehyde $)=1.8$, the yield of product was maximum, continue to increase the amount of cyclopentanone, the reaction yield basically stabilized.

Orthogonal experiment: Reaction at $30^{\circ} \mathrm{C}$, the alkali concentration, phase transfer catalyst and the amount of acid catalyst for the $\mathrm{L} 9\left(3^{4}\right)$ orthogonal experiment to optimize the reaction conditions from $1 \%$ alkali concentration, phase transfer catalyst is a polyethylene glycol-600, the amount of $0.7 \mathrm{~g}$, acid catalyst is $0.2 \mathrm{~g}$.

\section{Synthesis conditions of $\boldsymbol{\delta}$-decalactone}

Temperature on the reaction: Oxidation is an exothermic reaction, control the appropriate reaction temperature, in order to maintain a reasonable speed and avoid hydrogen peroxide oxidation behaviour of thermal instability, showing the importance of reaction ${ }^{12}$. So must choose a suitable reaction temperature.

Add 2-pentenyl cyclopentanone $10 \mathrm{~g}, 30 \mathrm{~mL}$ methanol, concentrated sulfuric acid $2 \mathrm{~mL}, 32 \mathrm{~g}$ hydrogen peroxide, change the reaction temperature, effects of different temperature on the reaction.

From the Fig. 3 we can see, the reaction at $50{ }^{\circ} \mathrm{C}$, the yield is better. Although the reaction temperature is conducive to positive, but will also accelerate the decomposition of hydrogen peroxide. Therefore, the temperature controlled at $50{ }^{\circ} \mathrm{C}$ is most reasonable.

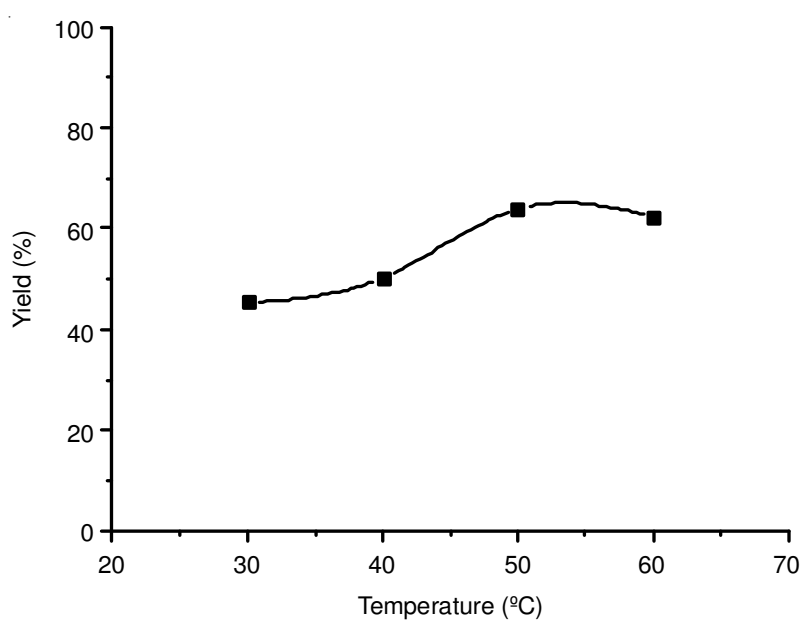

Fig. 3. Temperature on the reaction
Orthogonal experiment: At $50^{\circ} \mathrm{C}$, the amount of hydrogen peroxide and the amount of solvent, the amount of acid promoter for the $\mathrm{L} 9\left(3^{4}\right)$ orthogonal experiment to optimize the reaction conditions from the amount of hydrogen peroxide as $n$ (hydrogen peroxide): $n$ (2-pentenyl cyclopentanone) $=4: 1$, the reaction solvent is methanol, the amount of $30 \mathrm{~mL}$, acid accelerator dosage $2 \mathrm{~mL}$.

\section{Conclusion}

This work presents a new method for synthesizing title compounds by reaction of $n$-valeraldehyde and cyclopentanone via condensation, dehydration, reduction and oxidation. In the cyclopentanone and $n$-valeraldehyde condensation reaction, the reaction at $30{ }^{\circ} \mathrm{C}$, condensation optimized by orthogonal experiment reaction conditions, namely alkali concentration of $1 \%$ and the phase transfer catalyst is polyethylene glycol600 , its dosage is $0.7 \mathrm{~g}$, caid catalyst is $0.2 \mathrm{~g}$. Under these conditions, synthesis of 2-pentylidene cyclopentanone yield of ca. $86.3 \%$. Baeyer-Villiger oxidation reaction using hydrogen peroxide rearrangement as oxidant and through the orthogonal experiment, select the appropriate reaction conditions:reaction temperature is $50{ }^{\circ} \mathrm{C}$, hydrogen peroxide dosage of $n$ (hydrogen peroxide): $n$ (2-pentenyl cyclopentanone) $=4: 1$,solvent is methanol and the amount of $30 \mathrm{~mL}$, acid accelerator dosage $2 \mathrm{~m}$. In these conditions, synthesic result in high ester, production rate of $61.2 \%$.

\section{REFERENCES}

1. G.X. Wu and D.H. Hu, Flavour Fragrance Cosmetics, p. 21 (2000)

2. C.Y. Fan, Spices and Its application, Beijing: Chemical Industry Press, p. 19 (1990).

3. A. Corma, S. Iborra, M. Mifsud, M. Renz and M. Susarte, Adv. Synth. Catal. 346, 257 (2004).

4. P. Manat and J. Prapanpong, Tetrahedron Lett., 26, 2253 (1985).

5. G.X. Wu, D.H. Hu, C.H. Yang and Q.H. Kuang, Fine Specialty Chem., 17 (2001).

6. G. Bernd, H. Thomas and L.N. Ulrich, Chem. Ber., 117, 859 (1984).

7. Y.W. Zhao, W.M. Jia, Z.J. Wang and L.D. Liang, J. Shanghai Inst. Technol. (Nat. Sci.), 11, 100 (2011).

8. G.F. Ma, The New Baeyer-Villiger Catalytic Oxidation Reaction, Northwest Normal University (2007).

9. J.W. Liu, Nanjing Univ. Sci. Technol., (2006).

10. J.F. Xu, Y. Shen and J.J. Jiang, Fine Specialty Chem., 12, 12 (2004).

11. L.Z. Gao, Z.L. Cai and B.F. Wang, J. Luo Yang Univ., 15, 45 (2000).

12. J.W. Liu, T.T. Yan, H. Xuan, W. Mao and X.H. Peng, Jiangsu Chem. Ind, 33, 146 (2005). 